people, with their feeble human vision, have been slow to take seriously the UV signals of so many other creatures. Still, he welcomes the new work as "a nice, clean experiment." -S. MILIUS

\section{Dioxin Dumps}

\section{Burning exposed trash pollutes soil}

In poor urban areas of underdeveloped countries, people frequently set fire to refuse that accumulates along streets and in unofficial dumps. Research now suggests that this form of trash incineration leaves behind prodigious quantities of dioxins and related compounds, which other studies have shown can cause cancer and damage the liver and immune system.

As a consequence, open trash piles may expose people who live in the vicinity and scavenging animals to serious health risks, says Shinsuke Tanabe of Ehime University in Matsuyama, Japan. Other scientists note that the combustion products could be dispersing across borders on wind currents.

The chemicals can move from soil to body tissues by several means. They may be attached to dust that's kicked up and inhaled by animals and people. The substances may also be consumed accidentally or enter the body through the skin.

At open trash-burning sites in Cambodia, Vietnam, the Philippines, and India, Tanabe and his colleagues set out to measure five polychlorinated dibenzo- $p$-dioxins (dioxins) and eight related compounds mostly in the category of polychlorinated dibenzofurans (furans). Studies in industrialized nations have implicated ash and gases from municipal trash incinerators as sources of these chemicals. Furthermore, because open fires typically burn at lower temperatures than incinerators do, they're more likely to produce the compounds.

Tanabe's team tested 48 soil samples from five dumps where trash had been burned. The researchers also tested 13 soil samples from locales at least 30 kilometers from these dumpsites.

Soil from the dumps had much higher concentrations of the dioxins and furans than the other sites did. For example, at a dump in Phnom Penh, Cambodia, concentrations of 9 of the 10 studied dioxins and furans were at least 100 times greater than they were in soil away from the dump. The chemicals' concentrations in soil at this site and one in Hanoi, Vietnam, exceeded a threshold that in the United States and Japan triggers government intervention, Tanabe and his colleagues report in an upcoming issue of Environmental Science and Technology.

The study didn't include enough soil samples to give a reliable estimate of the magnitude of the problem caused by these dumps, says Karl-Werner Schramm, a dioxin researcher at the Institute of Ecological Chemistry in Neuherberg, Germany. Nevertheless, Schramm adds, the work supports a relationship between the incineration of junk and environmental problems.

This study appears to be the first to document that common methods of trash elimination in Asia are creating hazardous environmental concentrations of dioxins and related contaminants, says Johan Nouwen, who studies soil pollutants at the research institute Vito in Mol, Belgium. Trash burning "also could be an important problem in African and South American developing countries," he says.

Because diseases unrelated to pollution keep life expectancy short in many poor

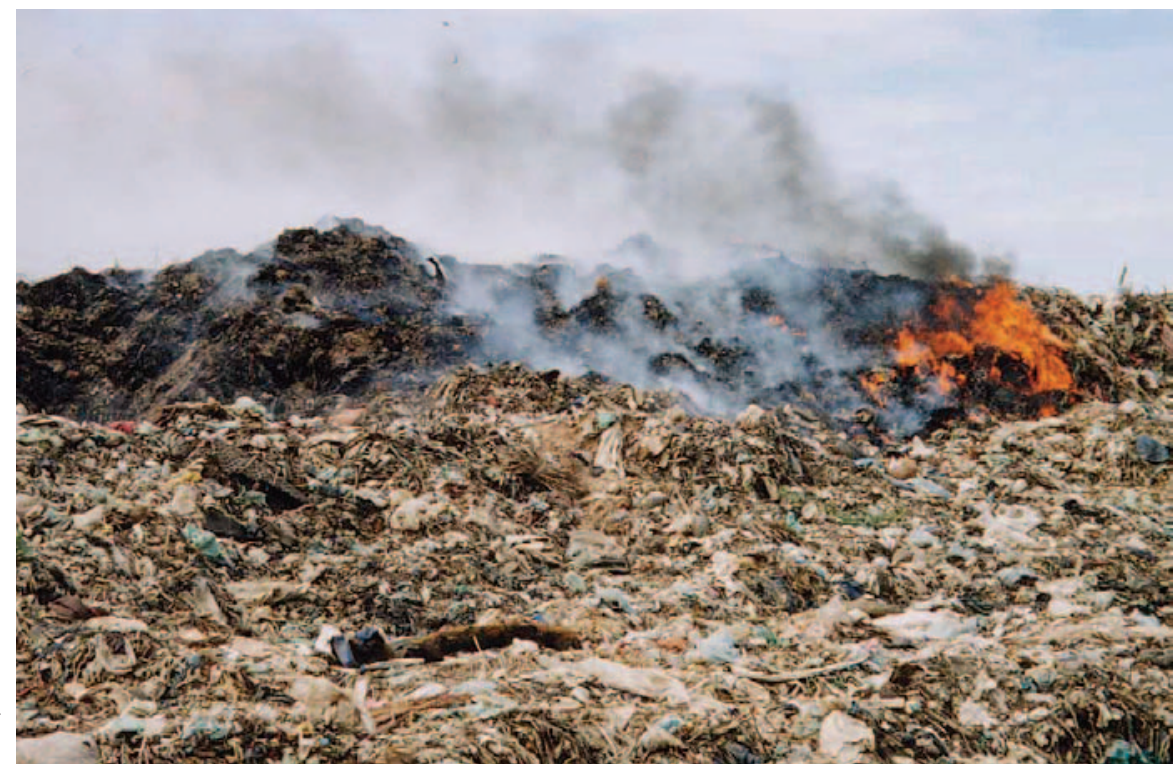

DIOXIN RISING Burning trash in the open, a common practice in many underdeveloped countries such as Cambodia, may create large quantities of illness-causing contaminants. countries, the newly documented threat may not become a high-priority health issue for the countries studied, Nouwen adds. However, air currents can carry dioxins and furans across national borders, so the health implications of small-scale trash burning deserve international attention, he says. - B. HARDER

\section{A Hard Little Lesson}

\section{Squeezed nanospheres grow superstrong}

Small is different. That's a fact of life for scientists studying virus-size chunks of matter called nanoparticles.

Now, the first-ever experimental determinations of the hardness of individual silicon nanospheres reveal just how different mechanical properties can be. The nanospheres are up to four times as hard as bulk silicon, such as the silicon wafers from which computer chips are made, report William W. Gerberich of the University of Minnesota, Twin Cities and his coworkers in the June Journal of the Mechanics and Physics of Solids. The diameter of the spheres ranged from 40 to 100 nanometers.

Gerberich's team, which includes researchers at Los Alamos (N.M.) National Laboratory, squished silicon nanospheres beneath a diamond point and caused atomic rearrangements to take place inside the spheres. From readings of the force on the spheres, as well as computer simulations of the squeezing process, the scientists calculated that the hardness of the silicon ranks between that of sapphire and diamond, two of the hardest materials known. Bulk silicon's hardness isn't in that ballpark.

If this hardness boost occurs in silicon when it's formed into nanospheres, says Gerberich, perhaps materials that are already extremely hard could be recast into yet harder forms. "I would like to try sapphire and silicon carbide," he says. The result could be new superhard materials for such uses as industrial polishing processes and making micromachines (SN: 7/22/OO, p. 56).

Gerberich says that the surprising boost in hardness results from a familiar metallurgy process called work hardening. It's normally achieved by operations such as hammering and rolling. However, unlike the ductile metals that are typically work hardened, bulk silicon is brittle, so it would shatter if subjected to those operations.

Besides hinting at practical payoffs, the new results "do a good job of extending our understanding of material behavior to a size range that has not been well studied before," comments Richard P. Vinci of Lehigh Uni- 
SGENGE
NEWS

\section{This Week}

versity in Bethlehem, Pa.

Particularly intriguing, he says, is that the number of atoms in the actual nanospheres approaches the number that can be included in a computer simulation. This near match suggests that researchers will soon be able to confidently predict from computer models how materials behave. "This ... opens up a world of possibilities for virtual-materials design," says Bob R. Keller of the National Institute of Standards and Technology in Boulder, Colo. -P. WEISS

\section{Morbid}

\section{Mystery Tour}

\section{Epidemic from China is encircling globe}

An outbreak of deadly pneumonia that seems to have begun in southern China spread this month to at least two other continents, including North America. Initial tests have given clues to the identity of the pathogen involved in the infection, which health officials have dubbed severe acute respiratory syndrome (SARS).

At least 300 cases of SARS have been tallied in mainland China, where the epidemic has apparently been smoldering since last November. Elsewhere, more than 450 cases and at least 17 deaths have been attributed to the disease, according to the World Health Organization (WHO) in Geneva.

The new epidemic "reminds us that... an emerging problem in one part of the world will soon be a problem for all of us," said Julie Gerberding, director of the Centers for Disease Control and Prevention (CDC) in Atlanta.

Beyond mainland China, Hong Kong has thus far borne the brunt of the outbreak, with at least 10 deaths among 286 cases. Epidemiologists have traced many of the other infections to a man who was hospitalized on Feb. 26 in Hanoi, Vietnam, after traveling from mainland China via Hong Kong. Several doctors who treated that patient later became ill. From Hanoi and Hong Kong, infected people traveling by airplane spread the disease to Europe, North America, other parts of Asia, and possibly Australia. At least 40 suspected cases have been identified in the United States.

Infections have occurred primarily through close and prolonged contact with sick individuals, WHO officials say. From 2 to 7 days after being exposed, an infected person suddenly develops a high fever and other flulike symptoms and suffers difficulty breathing. In some cases, respiratory problems are so severe that patients need artificial ventilators.

WHO, CDC, and numerous national health agencies have deployed teams of disease investigators and laboratory scientists to identify the pathogen and develop means to contain the outbreak. Investigators, who initially examined tissues from infected people for known viruses, bacteria, and other pathogens, suggest that a novel pathogen lies behind the epidemic.

Two candidate viruses had been identified by press time, one belonging to the paramyxovirus family and one to the coronavirus family. Paramyxoviruses produce well-known contagions such as measles and mumps. That family also includes the rare Nipah and Hendra viruses, both of which were discovered in the past decade after they emerged as deadly infections. Some coronaviruses commonly cause minor colds in people, but none has previously been linked to an outbreak as serious as the current one. - B. HARDER

\section{Fine Toothcomb}

\section{New fossils add to primate-origins debate}

Fossil hunters working in Egypt have unearthed jaw fragments and teeth belonging to the oldest known members of one of the main evolutionary branches of primates.

The 40-million-year-old specimens represent two ancient groups, one an ancestor of modern lorises-complete with a comblike set of lower front teeth that confirms its identity - and the other, of bushbabies, say anthropologist Erik R. Seiffert of Duke University in Durham, N.C., and his colleagues. These new finds double the age of the sparse fossil record for lorises and bushbabies, which with lemurs make up a primate group called the strepsirrhines. It originated in Africa at least 50 million years ago, the scientists conclude in the March 27 Nature.

"The new fossils date to near the evolutionary split of lorises and bushbabies from lemurs, which occurred perhaps 45 million years ago," Seiffert says.

Such estimates fit with the traditional notion that the first primates appeared around 65 million years ago. However, other researchers using DNA analyses have concluded that primates arose approximately 90 million years ago ( $S N$ : $4 / 20 / O 2, p$. 243).

In a comment published with the new report, Robert D. Martin of the Field

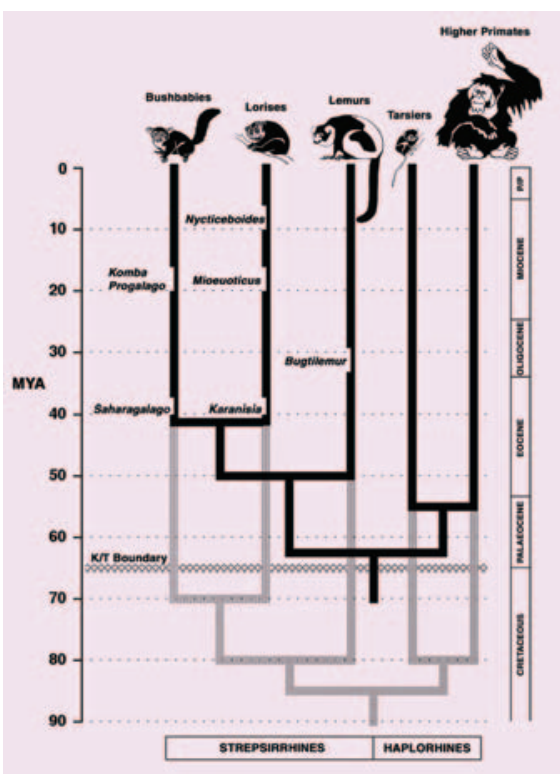

TANGLED TREE Primate evolutionary diagram shows the two main living groups, strepsirrhines and haplorhines, with known fossil forms of strepsirrhines. Traditional model of primate evolution (dark lines) contrasts with DNA-based version (shaded lines).

Museum in Chicago cites the genetic data in support of his view that strepsirrhines originated in southern Asia around 80 million years ago. In his view, lorises and bushbabies took a unique evolutionary route 10 million years later, perhaps when lemurs became isolated on the island of Madagascar after it separated from India.

"The timing and location of primate origins remains a complex problem," cautions evolutionary biologist Anne D. Yoder of Yale University, who has conducted primate-DNA studies. "Still, the new fossils from Egypt are terribly exciting."

Seiffert's group excavated a site in the Fayum Depression on the eastern edge of the Sahara Desert. They assign some of their finds to the genus Saharagalago, an ancestor of living bushbabies that weighed around $1 / 4$ pound. The rest come from the genus Karanisia, an ancient loris that tipped the scales at an estimated $2 / 3$ pound.

Of particular interest, the researchers say, are teeth at the front of a Karanisia lowerjaw fragment that form a toothcomb like that of today's strepsirrhines. The toothcomb consists of elongated, flattened teeth that angle sharply forward. Microscopic grooves on the fossil teeth indicate that Karanisia used its toothcomb for grooming, just as its living relatives do, Seiffert says.

Despite an intriguing find in Pakistan several years ago, no definitive lemur fossils have been found, Martin holds ( $S N$ : 10/20/01, p. 245).

"We need to find lemur fossils [at Fayum]," Seiffert says. Without such a find, he notes, fossil reconstructions of primate origin will remain shaky. - B. BOWER 